\title{
PERCEPÇÃO DA AVALIAÇÃO DA FORMAÇÃO DOS DOCENTES DO ENSINO MÉDIO DAS ESCOLAS DA REGIONAL I EM TECNOLOGIAS DIGITAIS \\ http://dx.doi.org/10.5902/2318133831919
}

\author{
Marcos Antonio Martins Lima ${ }^{1}$ \\ Andréa Moura da Costa Souza² \\ Blússia Tétis Brito Batista ${ }^{3}$ \\ Luís Antônio Rabelo Cunha ${ }^{4}$
}

\begin{abstract}
Resumo
A educação permanente, seja ela presencial, semipresencial ou à distância, são estimuladas pelas instituições e órgãos de fomentos como uma prática que favorece a formação do docente. $O$ presente artigo contextualiza a avaliação da formação docente em tecnologias digitais, assim como os seus desafios ao processo de integração dos conhecimentos adquiridos. Este estudo é resultado da pesquisa qualitativa desenvolvida entre os professores de português e matemática do ensino médio de duas escolas municipais de Fortaleza, localizadas na regional I, que participaram da formação semipresencial de 180h horas oferecida pelo FNDE/MEC, Secretaria Municipal de Fortaleza, em parceria com a UFC Virtual. Os resultados da pesquisa apontam que produzir uma mudança na cultura dos docentes para integrar as tecnologias digitais as atividades curriculares desenvolvidas em sala mostram-se desafiadores, mas outros fatores exógenos se mostraram pertinentes no decorrer da pesquisa.
\end{abstract}

Palavras-chave: avaliação, formação docente, tecnologias digitais.

\section{PERCEPTION OF EVALUATION OF TEACHER PROFESSIONAL QUALIFICATION OF ELEMENTARY EDUCATION OF ZONE 1 SCHOOLS IN DIGITAL TECHNOLOGIES}

\begin{abstract}
The permanent education, whether it is in person, semi-distant or by distance are stimulated by the institutions and entities of fostering as a practice that promotes the formation of teachers. This article contextualizes the evaluation of teacher education in digital technologies, as well as their challenges in the process of integration of the knowledge acquired. This study is the result of qualitative survey developed between the teachers of portuguese and mathematics in the high school of two municipal schools in the city of Fortaleza, located in regional I, who participated in the 180hs semi-distant training offered by FNDE/MEC, Secretaria Municipal de Fortaleza in partnership with the UFC Virtual. The research results indicate that produce a change in the culture of teachers to integrate the digital technologies to the curricular activities developed in class are challenging, but others exogenous factors were relevant during the research.

Key-words: evaluation, teacher training, digital technologies.
\end{abstract}

\footnotetext{
1 Universidade Federal do Ceará, Brasil. E-mail: marcos.a.lima@terra.com.br.

2 Instituto Federal do Ceará, Brasil. E-mail: andrea.souza@ifce.edu.br.

3 Universidade Federal do Ceará, Brasil. E-mail: blussia@hotmail.com.

${ }^{4}$ Centro Universitário Unichristus, Brasil. E-mail: coordadministracao01@unichristus.edu.br. \begin{tabular}{|l|l|l|l|l}
\hline Regae: Rev. Gest. Aval. Educ. & Santa Maria & v. 8 & n. 17 & Pub. contínua 2019
\end{tabular}
} p. 1-9 


\section{Introdução}

inserção das tecnologias digitais e sua utilização para fins pedagógicos
provoca uma intensa atividade que desencadeia na necessidade de formação
dos docentes. Todavia, avaliar a formação docente em tecnologias digitais é uma problemática que envolve várias questões, tais como a estrutura da escola, a organização pedagógica e as competências requisitadas dos docentes para desenvolver atividades curriculares com o uso das tecnologias digitais.

Este trabalho foi desenvolvido no contexto das Escolas Municipais da Regional I em Fortaleza. Foram escolhidas duas das 12 escolas de Fortaleza participantes do Projeto UCA/MEC e apoiadas pela Secretaria Municipal de Educação e pela Universidade Virtual/ Universidade Federal do Ceara. O projeto teve como intuito formar os docentes a integrar o currículo as tecnologias digitais usando laptops adaptados e cedidos pelo governo Federal ao programa.

O referencial teórico orienta-se a partir da abordagem avaliativa baseada em Stake, (1967); Scriven (1967). Incluímos também nessa pesquisa o processo de integração das tecnologias ao ensino (Fastrez; Meunier, 2007) e a formação docente (Paquay et al, 1998; Perrenoud, 1999).

\section{Referencial teórico}

A história da avaliação desenvolveu-se, em muitos dos seus momentos, atrelada a competência, pois esta é atestada em muitas vezes pela avaliação. $O$ termo avaliar tem origem no latim a valere que significa atribuir valor ou mérito, sendo concebida para controlar, certificar, criar hierarquias, valorizar, atestar um modelo de excelência, a avaliação abrange diversas categorias em funcionamento na sociedade ajudando a melhorar as praticas e procedimentos de programas (Perrenoud, 1999; Lima, 2005).

Para Stake (1967) a maioria das pesquisas educacionais deve estar a serviço da educação e proporcionar uma melhor compreensão de seus problemas práticos. Tendo a avaliação dois lados, sabe-se que o lado formal depende de elementos externos, inclusive de comparações controladas e do uso de testes padronizados: este modelo não é muito divulgada no Brasil, por não existir desenvolvido técnica psicométricas. O lado informal, por sua vez, depende de observações casuais, objetivos implícitos, normas intuitivas e julgamento subjetivo. Stake (1967) confirma que a técnica informal é mais praticada que a formal, pois se fundamenta na opinião de professores sobre a avaliação do programa, na sua lógica ou na reputação profissional dos responsáveis pela sua elaboração. (Fitzpatrick, Sanders, Worthen, 2004).

Inicialmente sua contribuição consistiu em estabelecer que a avaliação desempenha muitos papéis, mas possui um único objetivo: determinar o valor ou o mérito do que está sendo avaliado. A diferença entre papéis e objetivos é que o objetivo consistiria em oferecer uma resposta satisfatória aos problemas propostos pelas questões a serem avaliadas; os papéis referiam-se às maneiras como essas respostas são usadas. Scriven (1967) indica que os papéis formativo e somativo da avaliação que influenciaram o futuro e a prática da avaliação. Scriven (1967) mostrou que avaliação formativa deve ocorrer ao longo do desenvolvimento do programa, projetos e produtos educacionais, com vistas à proporcionar informações úteis para que os responsáveis possam promover aprimoramento do que está sendo objeto de implementação. 
A avaliação somativa, conduzida ao final de um programa de avaliação possibilita, ao seu futuro usuário, elementos para julgar a sua importância, o seu valor, o seu mérito. A questão da avaliação independente de objetivos foi colocada por Scriven (1967). Para o autor é preciso partir do princípio de que não se podem aceitar tranquilamente os objetivos fixados pelos avaliadores. Os objetivos precisam ser claros, quanto aos resultados desejados, para isso eles precisam ser avaliados antes de serem determinados.

Schwartz (1988) apud Tardif e Lessard (2011) lembra que, por vezes, os fins da docência é deixado as sombras, sabendo que todo trabalho humano possui um objetivo, um fim, o trabalho do docente também produz um fim, seja ele nomeado de diferentes formas como propõe os autores: "motivos, intencões, objetivos, projetos, planos, programas, planejamento, etc" que podem ser estabelecidos antes ou durante o trabalho. Os autores ressaltam que "os fins tambéms vão se transformando com a experiência do trabalhador" (p. 195) justificada pelo processo de formação e de aprendizagem que fazem que este modifique seus conhecimentos, sua identidade e suas relações com o trabalho docente.

Paquay et al (2001) relata que buscar saber mais a respeito das experiências e das formações dos docentes favorece nas escolhas das formações mais adequadas e que colaboram tanto para a melhoria das ações profissionais como na melhoria das ações de cunho pessoal. Altet (2007), define que

o professor profissional é, antes de tudo, um profissional da articulação do processo ensino-aprendizgem em uma determinada situação, um profissional da interaçao das significações partilhadas. Definimos o ensino como um processo interpessoal e intecional, que utiliza essencialmente a comunicação verbal e o discurso dialogico finalizado como meios para provocar, favorecer e levar ao êxito a apredizagem em uma dada situação; é uma pratica relacional finalizada. (p. 26)

O objetivo do docente é a aprendizagem do estudante. Para Altet (2007) foi acontece pelo seu profissionalismo, pela sua comunicação, mas também, pela interação entre todos, pelas condições criadas de aprendizagem e como são geridas em cada momento da sala de aula. A partir da evolução de contextos de aprendizagem que presenciamos, de situações e usos de recursos variados visando a aprendizagem, que a aplicação das tecnologias digitais se tornam recorrentes no currículo das disciplinas e consequentemente na sala de aula. De um lado como recurso para apreender e do outro como forma de inclusão digital. ( Souza, 2014).

Nesse contexto, no Brasil, a lei n. 12.249, de 11 de junho de 2010, instituiu o Regime Especial de Incentivos e, dentre eles, criou o Programa um computador por aluno e instituiu o Regime especial de aquisição de computadores para uso educacional Recompe (Brasil/Mec, 2010).

A nova lei de incentivos acarretou uma nova demanda de formação por parte dos docentes que precisam dominar e incluir as tecnologias digitais no currículo escolar. Para isso, o Ministério da Educação fez parcerias com as universidades federais para formar professores da rede pública municipal permitindo a apropriação de competências necessárias ao ato de incluir as tecnologias no currículo e consequentemente em sala de aula. Partindo deste cenário de formação institucional, esta ocorreu em 40 escolas 
municipais de Fortaleza concomitantemente que foram contempladas com o Programa um computador por aluno em 2014, prioritariamente aos docentes das disciplinas de Português e Matemática que optaram, receberam uma formação de 180 horas de forma semi-presencial. Este trabalho de pesquisa contextualiza a avaliação da formação docente em tecnologias digitais somente das escolas municipais da Regional I, assim que seus desafios ao processo de integração dos conhecimentos adquiridos.

\section{Procedimentos metodológicos}

Nossa pesquisa foi realizada com dez professores das disciplinas de Português e Matemática de duas escolas municipais da Regional I. A Regional I abrange 15 bairros: Vila Velha, Jardim Guanabara, Jardim Iracema, Barra do Ceará, Floresta, Álvaro Weyne, Cristo Redentor, Ellery, São Gerardo, Monte Castelo, Carlito Pamplona, Pirambu, Farias Brito, Jacarecanga e Moura Brasil. Nesta região moram cerca de 360 mil habitantes. A Regional I conta com 69 escolas municipais. Destas 12 optaram em participar do Programa um computador por aluno: o programa distribui laptops as escolas para que esses sejam integrados as aulas, esses aparelhos ficaram carinhosamente conhecidos como uquinha.

A opção metodológica dessa pesquisa foi qualitativa, longitudinal baseada em observações, relatos e relatórios quinzenais e ocorreu entre agosto e dezembro de 2014 em duas escolas municipais de ensino fundamental de Fortaleza. A escolha das escolas aconteceu pela proximidade entre elas e pela abertura e envolvimento dos diretores e docentes. A abordagem adotada foi qualitativa e privilegiou avaliar a percepção desses profissionais sobre a formação em tecnologias digitais. A pesquisa se concentrou em um grupo pequeno de escolas, mas envolvemos $95 \%$ dos docentes das disciplinas: língua Portuguesa e Matemática. O intuito maior foi avaliar pela da observação de suas narrativas e contextualizar os desafios ao processo de integração dos conhecimentos adquiridos na formação em tecnologias digitais. Participaram da formação dez professores. Ressaltamos que os docentes participantes têm experiência superior a três anos em docência. A formação foi desenvolvida nas escolas que o docente leciona, no horário disponível ao planejamento das aulas.

Este trabalho teve como objetivo avaliar a percepção dos docentes referente a infraestrutura disponível, a formação ofertada e os incentivos dados a capacitação. Algumas questões se sobressaíram no decorrer do trabalho em campo: sobre a infraestrutura, o que dizem os docentes: quais dificuldades encontradas para planejar as aulas com o uso do uquinha? Sobre a formação ofertada: Como elas estão acontecendo? Nos relatos sobre a capacitação, o que sobressaia sobre a apropriação, aplicação e perspectivas profissionais dos cursos de formação nas escolas?

\section{Resultados e discussões}

A implantação do Prouca iniciou com dois decretos: o primeiro decreto criou o Programa um computador por aluno - Prouca -, e o outro instituiu o Regime especial de aquisição de computadores para uso educacional - Recompe. Para equipar as escolas participantes desses programas, o MEC, junto com o Governo Federal e o Banco Nacional de Desenvolvimento Econômico e Social, disponibilizaram $R \$ 660$ milhões. 
O projeto teve continuidade nos anos subsequentes e, como parte da política nacional tecnológica educacional, o MEC expandiu atendendo mais escolas da rede pública, melhorando a infraestrutura, formando docentes e disponibilizando objetos de aprendizagem mapeados e disponibilizados gratuitamente para as instituições municipais. Segundo o portal do MEC (2010), "a infraestrutura de acesso à internet sem fio vai sendo instalada à medida que os computadores são entregues na escola. Posteriormente, professores recebem capacitação para uso do equipamento e utilização dessa tecnologia no processo pedagógico escolar".

O laptop disponível para as escolas possui quatro gigabytes de armazenamento, 512 megabytes de memória, tela de cristal líquido de sete polegadas, bateria com autonomia mínima de três horas e peso de até $1,5 \mathrm{~kg}$, além de ser resistente e equipado para a rede sem fio. O custo unitário do equipamento foi $R \$ 550,00$.

O Programa Prouca em Fortaleza ocorreu concomitantemente em 40 escolas. Para que a formação ocorresse da melhor forma seria necessário que os laptops estivessem na escola e que os mesmos fossem carregados semanalmente. Para facilitar 0 carregamento, todos os laptops são colocados no gabinete, este condiciona 32 máquinas e são plugados ao mesmo tempo no interruptor. Com os laptops carregados e in loco seria necessária uma conexão para que os docentes pudessem ter acesso a todos os recursos oferecidos e contemplados na formação. Todos os encontros começaram ocorrendo na escola proponente, mas devido as dificuldades apresentadas na infraestrutura da escola $A$ e esta não possuir sala apropriada para a formação e a falta de conexão sem fio, ocorreu da escola A se deslocar para a escola B que contava com uma sala equipada com computadores. A escola $B$ tinha uma sala apropriada e notebooks com conexão a cabo, mas esses recursos não eram suficientes para que a formação com 0 laptop uquinha ocorresse de forma adequada, pois os docentes precisavam se apropriar dos recursos oferecidos nesse laptop Educacional, marca Positivo, versão Mobo S7 que utiliza o sistema Linux e o sistema operacional UbuntUCA, os softwares utilizados são todos livres.

Quadro 1-

Infraestutura.

\begin{tabular}{|l|l|l|}
\hline \multicolumn{1}{|c|}{ Infraestrutura } & \multicolumn{1}{|c|}{ Escola A } & \multicolumn{1}{c|}{ Escola B } \\
\hline Conexão sem fio & Restrita, precária & Restrita, precária \\
\hline Conexão a cabo & $\begin{array}{l}\text { Existe somente para as } \\
\text { secretarias, diretoria. }\end{array}$ & $\begin{array}{l}\text { Existe para o laboratório de } \\
\text { informática. }\end{array}$ \\
\hline Sala para formação & $\begin{array}{l}\text { Não existe sala apropriada } \\
\text { para formação, se usou a a } \\
\text { biblioteca, mas a mesma } \\
\text { não tem nenhuma conexão } \\
\text { a Internet, o que dificultou a } \\
\text { formação. }\end{array}$ & $\begin{array}{l}\text { Utilizou o laboratório de } \\
\text { informática. }\end{array}$ \\
\hline Laptops recebidos & 64 & 64 \\
\hline
\end{tabular}

Fonte: dados da pesquisa. 
Analisando a infra-estrutura identificamos que nas duas escolas pesquisadas a infraestrutura era insuficiente. Notamos que se fosse esperar para que a estrutura estivesse adequada, as formações demorariam para acontecer, como citamos acima, o próprio portal do MEC informa que: "A infraestrutura de acesso à internet sem fio vai sendo instalada à medida que os computadores são entregues na escola. Posteriormente, professores recebem capacitação para uso do equipamento e utilização dessa tecnologia no processo pedagógico escolar". Percebemos que os computadores chegam nas escolas para depois serem criadas infra-estrutura para 0 uso adequado dos equipamentos.

Nesse tempo os equipamentos se tornam obsoletos e são pouco ou nunca utilizados. Foi confirmado pela Secretaria Municipal a autorização para instalação da fibra óptica com intuito de fornecer uma conexão de Internet nas escolas mais rápida, mas até então não tinham sido instalados. Para que o docente receba a formação adequadamente é necessário primeiro ter os laptops, segundo uma conexão sem fio e terceiro uma sala apropriada para que os docentes recebam o conteúdo. Ressaltando que o uso dos laptops pelos docentes com os alunos não necessariamente precisa ser em sala de aula, pode ser em outras dependências da escola ou fora dela, como nas atividades de campo.

As formações se organizaram em cinco módulos, como vemos no quadro 2.

Quadro 2 -

Formações ofertadas.

\begin{tabular}{|l|l|l|l|l|}
\hline \multicolumn{1}{|c|}{ Módulo 1 } & \multicolumn{1}{|c|}{ Módulo 2 } & \multicolumn{1}{c|}{ Módulo 3 } & \multicolumn{1}{c|}{ Módulo 4 } & \multicolumn{1}{c|}{ Módulo 5 } \\
\hline - Atividade 1 - & Atividade 6 - Criação & - Atividade 9 - & - Atividade 11 - & -Atividade 14: \\
Fórum de & e manutenção de & Portfólio 5 (em & fórum 4: Meu & portfólio 8 (em \\
Apresentação; & blog educacional; & grupo): Roteiro & projeto pessoal & grupo): \\
- Atividade 2 - & - Atividade 7 - Fórum & diagnóstico das & e profissional; & relatório de \\
Portfólio 1: & 3: Discussão sobre & escolas & - Atividade 12 - & infra-estrutura \\
Apresentação de & as postagens & acompanhadas; & Fórum 5: & e formação \\
atividade de & realizadas no blog; & - Atividade 10 - & Projeto e suas & das escolas; \\
Integração entre & - Atividade 8 - & Portfólio 6 & características; & - Atividade 15 - \\
recurso digital e o & Portfólio 4: & (individual): & - Atividade 13 - & Fórum 6: \\
currículo (em & Elaboração de Plano & Análise de OA. & Portfólio 7 (em & Desafio da \\
equipe); & de aula com um dos & & grupo): & implantação \\
- Atividade 3 - & recursos/ferramentas & & Projetos online & das TDIC na \\
Portfólio 2: Plano & postados no blog. & & e offline & escola. \\
de aula com uso & & & pesquisados. & \\
de recurso digital & & & & \\
(em equipe); & & & & \\
- Atividade 4 - & & & & \\
Fórum 2: Reflexão & & & & \\
texto "Sem medo & & & & \\
da tecnologia"; & & & & \\
- Atividade 5 - & & & & \\
Portfólio 3: & & & & \\
Estratégias para & & & & \\
desenvolvimento & & & & \\
\hline
\end{tabular}




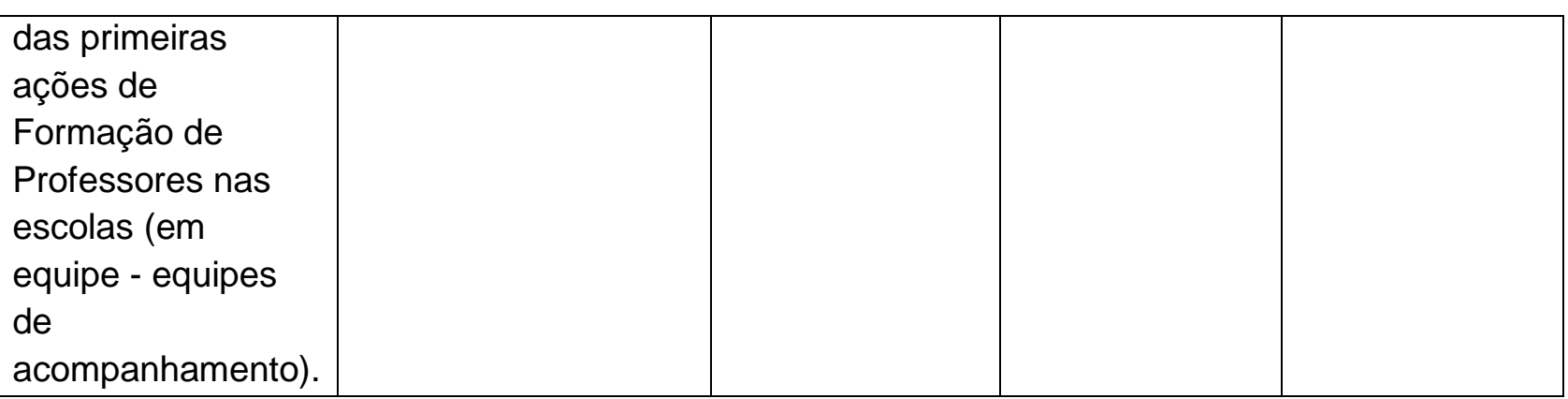

Fonte: dados da pesquisa.

A formação é semipresencial, os encontros presenciais ocorreram in loco, menos para a escola $A$ que se locomoveu para a escola $B$, de 15 a 15 dias, de agosto a dezembro de 2014. Os encontros virtuais ocorreram pela plataforma Sócrates/UFC. A plataforma disponibiliza, aos professores, o uso de ferramentas Web. O intuito de usar a plataforma é sempre favorecer a interação e a troca de experiências entre eles, mas como ficou restrito o cadastro por escola, não houve essa interação na plataforma pelos docentes, pois eles já se encontram na escola e as conversas sobre a formação e a troca de experiências ocorriam no lugar de trabalho.

Os docentes tiveram muitas dificuldades em se apropriar do sistema Linux e de outras ferramentas, muitos não usavam e-mails com frequência ou não tinham e-mail. Os trabalhos propostos na formação eram postados na plataforma Sócrates/UFC e muitos mostraram dificuldades, mas mesmo assim continuaram se superando e integrando está tecnologia nas atividades pedagógicas e curriculares como podiam. Mostraram-se unidos e solidários aos colegas de trabalho, auxiliando-os nas atividades propostas para as equipes. Com o intuito de aproximar o possível das atividades de manipulação dos recursos educacionais disponíveis no laptop do ponto de vista do utilizador e refletir sobre sua própria compreensão da atividade, observadas também no trabalho de Fastrez e Meunier (2007).

Nos relatos sobre a capacitação, o que se sobressai sobre a apropriação, aplicação e perspectivas profissionais dos cursos de formação nas escolas?

Sobre a capacitação, percebemos que a Secretaria Municipal de Educação de Fortaleza propunha três tipos de progressão: progressão por tempo de serviço; progressão por qualificação; promoção por titulação.

A progressão por qualificação que consta no Art. 17 é definida como a "passagem do servidor de um padrão de vencimento para o imediatamente superior, dentro do mesmo nível de classificação e estágio de carreira a que pertence" (Diário Oficial do Município/Fortaleza, n. 13.613, 2007).

Percebemos que a progressão por qualificação foi motivadora para que os docentes participassem do curso de formação, pois o curso propunha 180 horas de formação com certificação, horas suficientes e necessárias para a segunda progressão que exigia 180hs ou fazer a soma de carga horaria para uma primeira progressão que exigi 240 horas de formação.

Outro ponto que sobressaiu entre os docentes foi a vontade de atualizar os recursos utilizados em sala de aula para melhorar o aprendizado dos estudantes nas disciplinas de matemática e português, lembrando que essas disciplinas são os indicadores importantes para avaliações como o Ideb e o Spaece. O discurso entre eles foi um só: os estudantes estão cada vez mais conectados à Internet e as redes sociais, dessa forma usar os 
laptops se mostra um diferencial para a disciplina e um meio de melhorar a atenção dos estudantes. Ressaltamos o receio dos docentes para o não uso dos recursos educacionais propostos pelos mesmos e disponíveis nos laptops para os estudantes, pois os laptops têm acesso sem fio a Internet, atualmente restrito, mas as escolas estão em processo de instalação das fibras óticas que darão capacidade e velocidade de conexão.

\section{Considerações finais}

Concluímos sobre a percepção da avaliação da formação dos docentes do ensino médio das escolas municipais da Regional I em tecnologias digitais que a inciativa foi um avanço educacional. Ao observamos os três pontos pesquisados que foram infraestrutura, formação ofertada e relatos da capacitação, sobressai-se a vontade de fazer do Governo Federal e Municipal, mas ressaltamos a falta de sincronia entre as ações, pois na infraestrutura determinadas atuações dependiam de outras anteriores, assim estas seriam desenvolvidas com eficiência e eficácia se cada etapa tivesse sido atendida a seu tempo.

Como sugestão, propomos que a formação ofertada deve dar continuidade nas escolas para que os docentes se sintam mais seguros em integrar as tecnologias as suas aulas. Apesar das dificuldades que se apresentaram de apropriação, percebemos interesse dos docentes pela formação não somente para a progressão por qualificação, mas também pela integração das tecnologias as disciplinas.

\section{Referências}

ALTET, Marguerite. La formation professionnelle des enseignants: analyse de pratiques et situations pédagogiques. Paris: PUF, 1994.

ALTET, Marguerite. As competências do professor professional: entre conhecimentos, esquemas de ação e adaptação, saber analisar. In: PERRENOUD, Philippe et al (orgs.). Formando professores profissionais: quais estratégias? Quais competências? Porto Alegre: Artmed, 2001, p. 23-32.

BRASIL. Lei n. 12.249. Lei de regime de incentivos. Brasília, 11/06/ 2010.

BRASIL. Decreto n. 7. 750. Regulamenta o Prouca e o Reicomp: Regime Especial de Incentivo a Computadores para Uso Educacional. Brasília, 8 jun. 2012.

FASTREZ, Pierre; MEUNIER, Jean-Pierre. Compreendre comment l'apprenant comprend les Tice : retour sur les données issues de l'exepriérience. In : CHARLIER, Bernadette; PERAYA Daniel (orgs.). Transformations des regards sur la recherche en technologie de I 'éducation. Bruxelles: De Boeck, 2007, p. 91-106.

FITZPATRICK, Jody L; SANDERS, James R; WORTHEN, Blaine. Program evaluation: alternative approaches and practical guidelines. Boston: Pearson, 2004.

FORTALEZA. Plano de carreiras do município de Fortaleza para a educação. Fortaleza: Prefeitura Municipal, 2007.

LIMA, Marcos Antônio Martins. A avaliação no contexto histórico brasileiro recente da educação superior. Avaliação, Campinas, v. 10, n. 2, 2005, p. 83-95.

PAQUAY, Léopold et al. Formando professores profissionais: quais estratégias? Quais competências? Porto Alegre: Artmed, 2001.

PERRENOUD, Philippe. Avaliação da excelência à regulação da aprendizagem. Porto Alegre: Artmed, 1999. 
SCRIVEN, Michael. The methodology of evaluation. In: STAKE, Robert. Curriculum evaluation. AERA monograph series on evaluation, n, 1. Chicago: Rand Mcnally. 1967, p. 90-102.

SOUZA, Andrea Moura da Costa; LIMA, Marcos Antônio Martins. O uso web analysis na formação de tutores. ENCONTRO DE PÓS-GRADUAÇÃO E PESQUISA DA UNIFOR, 2014. Anais ... Fortaleza: Unifor, 2014.

STAKE, Robert E. The countenance of educational evaluation. Columbia: Teachers College Record, 1967.

TARDIF, Maurice; LESSARD, Claude. O trabalho docente: elementos para uma teoria da docência como profissão de interações humanas. Petrópolis: Vozes, 2007.

Marcos Antonio Martins Lima é professor associado na Universidade Federal do Ceará, economista, mestre em Administração, doutor em Educação. Coordenador do Grupo de Pesquisa em Avaliação \& Gestão Educacional vinculado aos Programas de Pós-Graduação em Educação e Administração e Controladoria da Universidade Federal do Ceará.

Orcid: https://orcid.org/0000-0001-5541-6220.

Endereço: Rua Dr. Gilberto Studart, 1290/902 - 60192-095 - Fortaleza - CE - Brasil. E-mail: marcos.a.lima@terra.com.br.

Andréa Moura da Costa Souza é professora no Instituto Federal do Ceará, administradora, mestre em Administração de Empresas e Educação, doutora em Educação. Coordenadora do grupo de pesquisa em Estudos organizacionais, empreendedorismo, inovação e ensino.

Orcid: https://orcid.org/0000-0003-1059-0756.

Endereço: Rua Padre Roma, 1055/401 - 60040-360- Fortaleza - CE - Brasil.

E-mail andrea.souza@ifce.edu.br.

Blússia Tétis Brito Batista é colaboradora do Grupo de Pesquisa em Avaliação \& Gestão Educacional vinculado ao Programa de Pós-Graduação em Educação da Universidade Federal do Ceará.

Orcid: https://orcid.org/0000-0002-9239-833X.

Endereço: Avenida da Universidade, 2853 - 60020-181 - Fortaleza - CE - Brasil.

E-mail: blussia@hotmail.com.

Luís Antônio Rabelo Cunha é administrador pela Universidade de Fortaleza e administrador hospitalar pela Universidade Estadual do Ceará.

Orcid: https://orcid.org/000-0002-7932-837X.

Endereço: Avenida Rui Barbosa, 700/602 - 60020-181 - Fortaleza - CE - Brasil.

E-mail: luisrabelo.ce@uol.com.br.

Recebido em 30 de março de 2018.

Aceito em 29 de outubro de 2018.

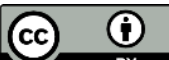

